\title{
Concentrations of choline and phosphocholine in the fetal brain of the laboratory rat are unaffected by maternal diets deficient in folic acid, choline or methionine
}

\author{
W. D. Rees and S. M. Hay \\ University of Aberdeen, Rowett Institute of Health and Nutrition, Greenburn Road, Bucksburn, Aberdeen AB21 9SB, UK
}

Studies have shown that giving choline supplements to pregnant animals leads to impressive improvements in the cognitive ability of the offspring throughout their entire lifespan and may protect them against the adverse effects of ageing ${ }^{(1-3)}$. Current evidence from human trials also suggests that there is an improvement in cognitive function in the offspring of mothers who eat more choline ${ }^{(4,5)}$. The ways in which choline helps the fetal brain develop are not fully established, but it is known to improve the growth of specific brain regions ${ }^{(6)}$ possibly by contributing to the synthesis of cell membranes via phosphocholine. The metabolism of choline is closely linked to that of folic acid and methionine and it is possible that maternal diets deficient in any one of these components may impact on the availability of choline or phosphocholine in the fetal brain. The aim of the present study was to measure choline and phosphocholine concentrations in the fetal brain of rats fed B vitamin deficient diets.

Pregnant rats were fed one of five experimental diets; complete diet (Control), deficient in folic acid (-F), deficient in folic acid and low in choline (-F LC), deficient in folic acid and low in methionine (-F LM) or one deficient in all three key methyl donors, folic acid, choline and methionine (-F LM LC) and for comparison one group of animals were fed the stock diet (Stock) ${ }^{(7)}$. Animals were killed on d21 of gestation and the fetal brains were harvested. Choline and phosphocholine concentrations were measured as described previously ${ }^{(7)}$. Data were analysed by ANOVA.

\begin{tabular}{|c|c|c|c|c|c|c|c|c|}
\hline Diet & & Control & $-F$ & -F LM & -F LC & -F LM LC & Stock diet & $P$ value \\
\hline \multirow[t]{2}{*}{ Choline content (nmol/g tissue) } & mean & 250.9 & 201.3 & 243.5 & 240.0 & 237.7 & 258.9 & 0.174 \\
\hline & sem & 10.4 & 9.6 & 4.1 & 14.7 & 10.8 & 23.5 & \\
\hline \multirow[t]{2}{*}{ Phosphocholine content (nmol/g tissue) } & mean & 1442.1 & 1262.5 & 1369.5 & 1397.3 & 1357.6 & 1267.4 & 0.497 \\
\hline & sem & 82.9 & 74.2 & 127.4 & 48.2 & 29.8 & 77.9 & \\
\hline \multirow[t]{2}{*}{ Brain Weight (mg) } & mean & 73.8 & 88.8 & 78.2 & 85.3 & 77.9 & 86.8 & 0.360 \\
\hline & sem & 4.5 & 9.0 & 8.8 & 5.5 & 2.4 & 5.0 & \\
\hline \multirow[t]{2}{*}{ Litter size } & mean & 14.5 & 13.7 & 13.6 & 12.3 & 13.1 & 13.1 & 0.780 \\
\hline & sem & 0.5 & 0.4 & 1.9 & 1.7 & 0.9 & 0.9 & \\
\hline$n$ & & 8 & 6 & 5 & 6 & 7 & 8 & \\
\hline
\end{tabular}

Concentrations of both free choline and phosphocholine in the fetal brain were unaffected by the provision of folic acid, methionine or choline in the maternal diet. Previously we have shown that the phosphocholine content of the maternal liver was reduced by about $20 \%$ in the dams fed these low choline experimental diets, and when combined with a low methionine diet, phosphocholine concentrations were reduced by approximately $60 \%{ }^{(7)}$. Conversely folate deficient diets increased free choline in the maternal liver by approximately two fold ${ }^{(7)}$. Despite these marked changes in maternal choline metabolism there were no changes in the concentrations of either choline or phosphocholine in the fetal brain. This study suggests that the benefits of choline supplementation on neural development may be an indirect consequence of improved maternal metabolism.

1. Meck WH, Williams CL, Cermak JM, Blusztajn JK (2007) Front Integr. Neurosci. 1, 7.

2. Meck WH, Williams CL (1999) Developmental Brain Research 118, 51-59.

3. Meck WH, Williams CL (2003) Neuroscience and Biobehavioral Reviews 27, 385-399.

4. Wu BTF, Dyer RA, King DJ, Richardson KJ, Innis SM (2012) PLoS ONE 7, e43448.

5. Boeke CE, Gillman MW, Hughes MD, Rifas-Shiman SL, Villamor E, Oken E (2013) Am. J. Epidemiol.

6. Craciunescu CN, Albright CD, Mar MH, Song J, Zeisel SH (2003) Journal of Nutrition 133, 3614-3618

7. Maloney CA, Hay SM, Rees WD (2007) Br. J Nutr 97, 1090-1098. 